\title{
A rare case of an unexpected aortopulmonary window
}

\begin{abstract}
Background: Aorto-pulmonary window is a rare heart disease occurring in $0.1-0.2 \%$ of patients with congenital cardiac disease and results from an incomplete development of the conotruncal septum. In half of the cases aorto-pulmonary windows are associated with other anomalies. This condition can occur on its own or with other heart defects such as: tetralogy of fallot, pulmonary atresia, atrial septal defect, interrupted aortic arch, truncus arteriosus, patent ductus arteriosus. Fifty percent of patients usually have no other heart defects. Babies that have a hole in between the aorta and pulmonary artery have blood from the aorta that flows into the pulmonary artery, and as a result too much blood flows to the lungs. This causes high blood pressure in the lungs (a condition called pulmonary hypertension) and congestive heart failure. Symptoms can include: delayed growth, irritability, rapid heartbeat, heart failure, infections of the lungs.

Case: We describe a case of aortopulmonary window incidentally found during surgery for a Type A interrupted aortic arch and repaired uneventfully.

Conclusions: In our case the anomaly was not diagnosed until the thoracotomy but anatomy allowed surgeon to perform the closure of the window.
\end{abstract}

Keywords: Rare disease; Aortopulmonary window; Tetralogy of Fallot

\section{Introduction}

Aortopulmonary window is a rare cardiac anomaly occurring in $0.1-0.2 \%$ of patients with congenital cardiac disease and results from an incomplete development of the conotruncal septum. Aortopulmonary window is defined as the presence of a communication between two great vessels, the ascending aorta and the main pulmonary artery or the right pulmonary artery.

\section{Case Description}

A three weeks old boy was admitted to the Congenital Cardiac Surgery Unit with the diagnosis of type A interrupted aortic arch, patent ductus arteriosus and ventricular septal defect. Surgical indications were confirmed. In theatre, after the median sternotomy and the longitudinal pericardiotomy, a small type 1 aortopulmonary window (APW) according the Richardson et al. classification [1] was incidentally detected. Both the aortic and pulmonary ends were ligated (Figure 1) and the defect transacted.

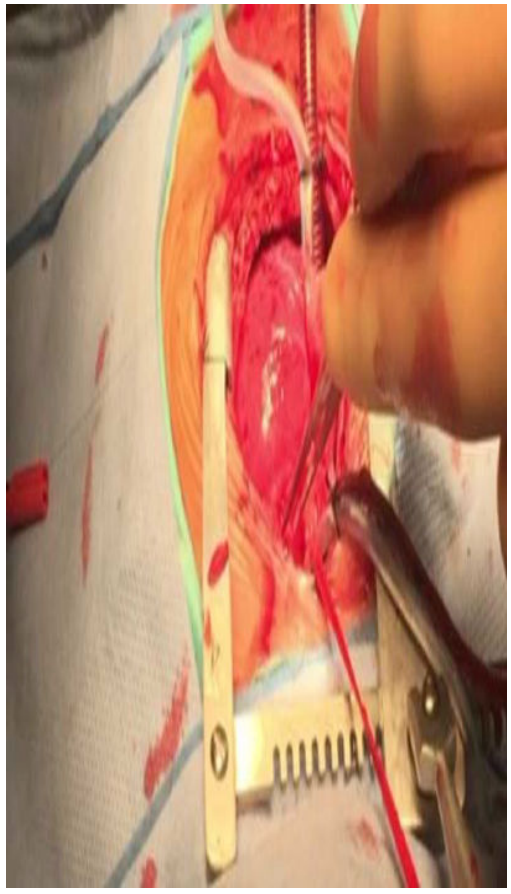

Figure 1: Aortic and pulmonary ends ligation.

\section{Discussion}

These anomalies are very rare and can be associated, as in our case, with other anomalies like the interrupted aortic arch,
Luisa Carini*, Maria Sole Cantarano, Manuela Lombardi, Stefano Congiu, Paolo de Siena and Federico Bizzarri

Department of Cardiology, University' La Sapienza Roma 1, Italy

*Author for correspondence:

luisa.carini@uniroma1.it

Tel: +393491236003

Submitted: 09 October 2017

Accepted: 13 November 2017

Published online: 20 November 2017 
ventricular septal defect and Tetralogy of Fallot [2]. In literature there are several classifications of APW and one of the most used is made by Richardson et al. that describe three types of APW [1-3]:

- Type I: typical aortopulmonary septal defect or window;

-Type II: distal aortopulmonary septal defects in which the ascending aorta communicates with the origin of the right pulmonary artery;

- $\quad$ Type III: anomalous right pulmonary artery origin from ascending aorta, or hemitruncus arteriosus. Prenatal diagnosis is rare. It can be done only in patients without cardiac connections abnormalities prenatally on the standard three-vessel view.

The aorto-pulmonary window is a rare malformation that consists of an alteration in the formation of the aortopulmonary septum and is configured with a communication between ascending aorta and pulmonary artery trunk in the presence of adequate semilunar valves [4]. This lesion may be isolated or in combination with other complex cardiac abnormalities. The defect is generally located between the lateral left side of the aorta and the left side wall of the pulmonary artery. The diameter of the defect is varied, but in general it is of such size as not to be restrictive. A particular syndrome that deserves to be remembered is the combination of a wide pulmonary aortic window, with the right pulmonary artery that originates separately from the lateral posterior wall of the ascending aorta, interruption of the aortic artery and patent arterial duct [5]. We still recall the possibility of abnormal coronary origin that may arise from the window or pulmonary artery. The aortopulmonary window from a pathophysiological point of view behaves like a major arterial duct that causes severe myocardial infarction from early infancy. With a certain frequency, patients with aorto-pulmonary window, who are already in preoperative phase, to give stability to cardiovascular conditions need to be treated with resuscitatory maneuvers: inotropic support, prostaglandin infusion and assisted mechanical ventilation. Surgical correction, even in this anomaly, is implied with the moment of diagnosis unless the defect is truly restrictive [6-8]. An incision right at the window at the front half of the defect allows excellent exposure and facilitates the closure with patches of aortic and pulmonary sinus, paying particular attention to their reconstruction to avoid obstructions or In this patient, the large shunt that is created for the naturally wide window size develops a pulmonary obstructive disease within the first year of life. Because of the fall in lung resistance, clinical conditions, shortly after the neonatal period, are expected to deteriorate rapidly. If the lung circulation does not fall, myocardial insufficiency will be a cause of rapid clinical deterioration, but the life expectancy of these patients remains limited over time due to severe pulmonary hyper flow. Associated lesions can contribute to significantly altering natural history. If there is aortic interruption, these patients immediately after their birth are rapidly encountered in a massive cardio circulatory collapse. Specific postoperative problems are pulmonary hypertension, residual shunt and pulmonary hypertensive crisis.

In current literature there is not enough information about APW, and it is possible to say that the only tools available for postnatal diagnosis are electrocardiogram, echocardiogram and auscultation, the same instruments used for differential diagnosis. In fact, a differential diagnosis with patent ductus arteriosus and common truncus arteriosus can be done by the presence of the signs such as aortic systolic murmur and with signs of left ventricular hypertrophy on electrocardiogram $[9,10]$. Also, the quality of the peripheral pulse, as well as the loud diastolic murmur, can be used to diagnose APW. The presence of right ventricular hypertrophy, or combined ventricular hypertrophy, in an infant with aortic stenosis suggests complicating associated right-sided anomalies. In our case APW was not diagnosed until the thoracotomy and so the treatment was unprogrammed, but the anatomy of the anomaly allowed the surgeon to perform the closure of the windows. The main operation was carried on routinely and the course was uneventful. The patient was admitted to the ICU with minimal inotropic support and his recovery was satisfactory without complications. At follow-up 12 months after repair the patient denied any symptoms or complication.

\section{Conclusion}

The surgery for correction of APW has evolved over years, currently an open repair on cardiopulmonary bypass (CPB) with a single patch technique yields good results [11,12]. Mortality is affected by association of pulmonary hypertension and other cardiac malformations. 
Background: Aorto-pulmonary window is a rare heart disease occurring in $0.1-0.2 \%$ of patients with congenital cardiac disease and results from an incomplete development of the cono-truncal septum. In half of the cases aorto-pulmonary windows are associated with other anomalies. This condition can occur on its own or with other heart defects such as: tetralogy of fallot, pulmonary atresia, atrial septal defect, interrupted aortic arch, truncus arteriosus, patent ductus arteriosus. Fifty percent of patients usually have no other heart defects. Babies that have a hole in between the aorta and pulmonary artery have blood from the aorta that flows into the pulmonary artery, and as a result too much blood flows to the lungs. This causes high blood pressure in the lungs (a condition called pulmonary hypertension) and congestive heart failure. Symptoms can include: delayed growth, irritability, rapid heartbeat, heart failure, infections of the lungs.

Case: We describe a case of aortopulmonary window incidentally found during surgery for a Type A interrupted aortic arch and repaired uneventfully.

Conclusions: In our case the anomaly was not diagnosed until the thoracotomy but anatomy allowed surgeon to perform the closure of the window.

\section{References}

1. Richardson JV, Doty DB, Rossi NP, Ehrenhaft JL. The spectrum of anomalies of aortopulmonary septation. J. Thorac. Cardiovasc. Surg. 78(1): 21-27 (1979).

2. Alsoufi B, Schlosser B, McCracken C, et al. Current Outcomes of Surgical Management of Aortopulmonary Window and Associated Cardiac Lesions. Ann. Thorac. Surg. 102(2): 608-614 (2016).

3. Jacobs JP, Quintessenza J, Gaynor JW, Burke RP, Mavroudis C. Congenital Heart Surgery Nomenclature and Database Project: aortopulmonary window. Ann. Thorac. Surg. 69: S44-S49 (2000).

4. Fotaki A, Novaes J, Jicinska H, Carvalho JS. Fetal aortopulmonary window: case series and review of the literature. Ultrasound. Obstet. Gynecol. 8: 562 (2016).

5. Mody MR, Nadas AS, Bernhard WF. Aortic Stenosis in Infants. N. Engl. J. Med. 276(15): 832-838 (1967).

6. Shamim AA, Khan MZ, Atiq MA, Khan MA, Amanullah MM. Surgical correction of aorto-pulmonary window: a rare and lethal cause of pulmonary hypertension. J. Pak. Med. Assoc. 61(8): 836-838 (2011).

7. Celebi A,Yucel I, Balli S, Kucuk M. Two cases of transcatheter closure of central aortopulmonary shunts. Texas. Heart. Ins. J. 43: 3 (2016).

8. Kumar A, Singh DK, Gupta VK. Aortopulmonary Window: A Rare Congenital Heart Defect. J. Clin. Diagn. Res. 10(8): 1-2 (2016).

9. Yüksel İÖ, Köklü E, Arslan Ş, Üreyen ÇM, Küçükseymen S. Aortopulmonary window in adulthood: Surviving at 22 years without intervention or pulmonary vascular disease. Turk. Kardiyol. Dern. Ars. 44(4): 332-334 (2016).
10. García C, Álvarez T, Bravo C, et al. Prenatal Diagnosis of an Aortopulmonary Window With an Interrupted Aortic Arch. J. Ultrasound. Med. 35(10): 2087-2093 (2016)

11. Wang Z, Cai X. Transcatheter intervention in a child with scimitar syndrome. Cardiovasc. J. Afr. 27(3): e9-e11 (2016).

12. Kose M, Ucar S, Emet S, Akpinar TS, Yalin K. A Case of Aortopulmonary Window: Asymptomatic until the First Pregnancy. Case. Rep. Cardiol. 93: 5253 (2015). 